\title{
UMA LEITURA DA INCLUSÃO A PARTIR DO PENSAMENTO DE PAUlo Freire*
}

Carlos Alberto Marques**

\section{RESUMO}

Várias condições vêm sendo consideradas como "desviantes” pela sociedade. Ser negro, ser velho, ser criança, ser mulher, ser deficiente representam condições de subalternidade de direitos e de desempenho de funções sociais. É nesse contexto que as relações sociais manifestam-se de diversas maneiras, produzindo as mais variadas formas de preconceito e controle, atitudes contra as quais Paulo Freire sempre se posicionou com extrema veemência. Neste trabalho, foram utilizadas as categorias da historicidade, da inconclusão, da conscientização, da comunhão, do diálogo e da libertação. A postura antidiscriminatória e antisegregacionista de Freire posiciona-o como um dos mais importantes teóricos do movimento de ruptura com o paradigma da exclusão, na busca pela instauração do que hoje denominamos de paradigma da inclusão social.

Palavras-chave: inclusão; exclusão; diversidade; paradigma.

Nunca falo da utopia como uma impossibilidade que, às vezes, pode dar certo. Menos ainda, jamais falo da utopia como refúgio dos que não atuam ou [como] inalcançável pronúncia de quem apenas devaneia. Falo da utopia, pelo contrário, como necessidade fundamental do ser humano. Faz parte de sua natureza, histórica e socialmente constituindo-se, que homens e mulheres não prescindam, em condições normais, do sonho e da utopia. (FrEIRE, 2001a, p. 85)

\footnotetext{
* Artigo recebido em 3/6/2006 e aprovado em 21/9/2006. Este texto faz parte dos estudos realizados na pesquisa Uma leitura crítica da Educação Especial a caminho da inclusão, financiada pelo CNPq.

** Doutor em Comunicação e Cultura pela Universidade Federal do Rio de Janeiro e professor da Universidade Federal de Juiz de Fora. E-mail: carlosalbertomarques@ diverso.gdhost.net
} 
Com base no pensamento de Paulo Freire, propomo-nos a fazer algumas análises sobre a questão da diversidade humana e suas implicações no processo de mudança por que vem passando o mundo na atualidade.

As reflexões acerca do ser humano devem levar em conta o fato de que o esforço de se conceituá-lo representa apenas a busca de traços genéricos que possam favorecer a identificação e caracterização de tão complexa criatura. Dessa forma, o conceito de ser humano não pode, em hipótese alguma, ser tomado como um conceito unívoco, ou seja, não existe, de fato, uma unidade de manifestações emocionais, intelectuais ou físicas que possa reduzir os habitantes dos diversos recantos do planeta a um único conjunto de intenções e manifestações.

Observa-se que muitas condições sociais têm sido consideradas e tratadas como desviantes, fato que reflete, nas diversas situações, um julgamento social que se requinta na medida em que as sociedades aprimoram-se tecnologicamente em função de valores e de atitudes culturais específicas. Em algumas sociedades, ser negro, ser velho, ser mulher, ser criança, ser deficiente etc. representa uma condição de subalternidade de direitos e de desempenho de funções sociais. É nesse contexto de complexa trama de relações sociais que se manifestam, nas diversas formas de controle, discriminação e opressão, atitudes contra as quais Paulo Freire sempre se posicionou de forma contundente. Segundo o autor,

Aceitar e respeitar a diferença é uma dessas virtudes sem o que a escuta não se pode dar. Se discrimino o menino ou a menina pobre, a menina ou o menino negro, o menino índio, a menina rica; se discrimino a mulher, a camponesa, a operária, não posso evidentemente escutálas e se não as escuto, não posso falar com eles, mas a eles, de cima para baixo. Sobretudo, me proíbo entendê-los. Se me sinto superior ao diferente, não importa quem seja, recuso-me escutá-lo ou escutála. O diferente não é o outro a merecer respeito, é um isto ou aquilo, destratável ou desprezível. (FREIRE, 1996, p. 136)

Ao longo da história, pode-se constatar que a sociedade quase sempre se apresentou preconceituosa e com práticas discriminatórias em uma trama de relações, em que o tratamento dispensado aos portadores de deficiência constitui um dos maiores de todos os exemplos. A problemática vivida por tais pessoas demonstra que os conceitos e as 
práticas vivenciadas nessa sociedade são determinados pela ideologia dominante, acarretando um esvaziamento de significado, como se tais pessoas não fossem capazes de escolher, de decidir e de agir, estando, em suma, condenadas ao ostracismo e sujeitas ao olhar piedoso da sociedade. Neste sentido, diz Marques (1992, p. 8), que o que temos

é uma sociedade impregnada de preconceitos e de um espírito de competição que, por prepotência dos ditos "normais", procura estabelecer os limites do outro, como se este fosse um inválido e, conseqüentemente, um ser digno apenas de "caridades" marginalizadoras e humanamente humilhantes.

Freire alerta para a "malvadeza" a que estamos expostos em um mundo onde a ética do mercado sobrepõe-se à ética do respeito e do amor entre os homens. Nas suas palavras:

O discurso da globalização que fala da ética esconde, porém, que a sua é a ética do mercado e não a ética universal do ser humano, pela qual devemos lutar bravamente se optamos, na verdade, por um mundo de gente. [...]

Há um século e meio Marx e Engels gritavam em favor da união das classes trabalhadoras do mundo contra sua espoliação. Agora, necessária e urgente se fazem a união e a rebelião das gentes contra a ameaça que nos atinge, a negação de nós mesmos como seres humanos submetidos à "fereza" da ética do mercado. (1996, p. 144-145)

A realidade é assim mesmo, que podemos fazer? É uma frase que expressa bem o fatalismo dessa ideologia e sua indiscutível vontade imobilizadora. É exatamente por causa disso que devemos estar atentos quanto ao poder do discurso ideológico que tem o poder de persuasão indiscutível, visto que nos ameaça de anestesiar a mente, de confundir a curiosidade, de distorcer a percepção dos fatos, das coisas, dos acontecimentos.

Cumpre ressaltar que esse discurso não pode explicitar seu caráter discriminatório. A ideologia dominante, em seu pretenso berço de excelência, procura passar a idéia de preocupação e de dedicação à causa dos desafortunados da sorte. Paulo Freire critica veementemente essa postura ao indagar:

Que excelência é essa que consegue "conviver com mais de um bilhão de habitantes do mundo em desenvolvimento que vivem na pobreza", 
para não falar em miséria. Para não falar também na quase indiferença com que convive com bolsões de pobreza e "bolsos" de miséria no seu próprio corpo, o desenvolvido. Que excelência é essa, que dorme em paz com a presença de um sem-número de homens e de mulheres cujo lar é a rua, e deles e delas ainda se diz que é a culpa de na rua estarem. Que excelência é essa que pouco ou quase nada luta contra as discriminações de sexo, de classe, de raça, como se negar o diferente, humilhá-lo, ofendê-lo, menosprezá-lo, explorá-lo fosse um direito dos indivíduos ou das classes, ou das raças ou de um sexo em posição de poder sobre o outro. Que excelência é essa que registra nas estatísticas, mornamente, os milhões de crianças e, se mais resistentes, conseguem permanecer, logo do mundo se despedem. (FreIRE, 2001b, p. 94-95)

Esse discurso é sustentado pela concepção funcionalista de sociedade, segundo a qual o todo social caracteriza-se como uma grande engrenagem, cujas peças (pessoas, grupos e classes) ocupam e desempenham funções bem definidas. Para assegurar o bom funcionamento da máquina social, é necessário que todas as peças desempenhem com perfeição seu papel, mantendo a harmonia e a eficácia da engrenagem.

Associada a essa concepção de sociedade está a idéia de corpo saudável e produtivo. Um corpo deficiente é considerado um corpo doente e improdutivo, sobre o qual as relações de poder têm alcance imediato. Elas investem nele, dirigem-no, obrigam-no a situações determinadas por um conceito social mais abrangente. Esse investimento ético-político no corpo está ligado à sua utilização econômica. Pensar assim é desacreditar na capacidade do homem de manifestar-se como ser no mundo. É negar-lhe, como acredita Freire, a condição de sujeito, de participar da dinâmica da sociedade. É colocar o portador de deficiência como um ser incapaz, de tratá-lo como animal, negando-lhe sua própria subjetividade. Freire (2002, p.121) afirma

que os homens são seres da práxis. São seres do que fazer, diferentes, por isso mesmo, dos animais, seres do puro fazer. Os animais não "admiram" o mundo. Imergem nele. Os homens, pelo contrário, como seres do que fazer emergem dele e, objetivando-o, podem conhecê-lo e transformá-lo com seu trabalho.

Ao ser concebida como um corpo estruturado com órgãos, no qual cada órgão tem uma função social muito precisa, a sociedade estabelece as funções de cada indivíduo e determina quem pode e quem 
não pode desempenhar os diversos papéis sociais. Por analogia ao corpo humano, os órgãos devem se relacionar entre si, trazendo uma harmonia fisiológica para esse corpo, não devendo existir órgãos estragados ou em mau funcionamento. Nas palavras de Ribas (1989, p. 15), "Um corpo com órgãos 'deficientes' não é um 'corpo social' bem estruturado e em ordem. Dessa forma, não é toda a sociedade que estaria fragmentada, mas apenas uma parte dela seria considerada "fora do normal'". Além do suposto "prejuízo funcional" causado ao corpo social, está também presente o sentido de que um "órgão estragado" poderia "contaminar" os demais, devendo, por isso, ser afastado do conjunto dos "órgãos sadios".

Aplica-se, aqui, a metáfora da "maçã podre" em um cesto de "maçãs boas": o "fruto bom" perderia o seu valor se mantido ao lado do "fruto podre". Ainda segundo Ribas (1989, p. 15-16),

Nessa sociedade a ordem é por demais valorizada. Sempre ouvimos as pessoas dizerem que uma sociedade sem ordem jamais chegará ao progresso. Sempre ouvimos também que um órgão qualquer que esteja apresentando uma disfunção pode contaminar o resto do "corpo social". Estas são idéias facilmente transponíveis para o nosso corpo humano individual. Um corpo deficiente seria, sob esse raciocínio, um corpo que apresenta necessariamente disfunções, incapacidades e não estaria em ordem. Um corpo que não está em ordem conseqüentemente não poderá alcançar o progresso tão desejado. Logo, será um corpo fadado a não ter realizações, a não ter progressos, a ser sempre dependente.

O resultado dessa transposição de valores funcionais é a marginalização dos deficientes, aqui tratados como "desviantes". Nesse sentido, a deficiência assume a marca da incapacidade produtiva e da dependência econômica, fazendo de seus portadores seres inadaptados aos padrões de aceitabilidade com que a sociedade classifica os seus membros.

Ao refletir sobre a prática autoritária presente no modelo de educação bancária, Freire ressalta a patologização do desvio como uma das práticas utilizadas pela ideologia dominante na tentativa de preservação do poder pelas classes opressoras. Diz ele:

Para isto se servem da concepção e prática "bancárias" da educação, a que juntam toda uma ação social de caráter paternalista, em que os oprimidos recebem o nome simpático de "assistidos". São casos individuais, meros "marginalizados", que discrepam da fisionomia 
geral da sociedade. "Esta é boa, organizada e justa. Os oprimidos, como casos individuais, são patologia da sociedade sã, que precisa, por isto mesmo, ajustá-lo a ela, mudando-lhes a mentalidade de homens ineptos e preguiçosos". (2002, p. 60)

Considerados como patologias sociais, os casos de desvios constituem objeto permanente de vigilância e de exclusão do convívio social. Tais pessoas representam uma categoria historicamente oprimida e discriminada. Vítimas da rejeição e/ou da compaixão social, estiveram quase sempre à margem do convívio com os cidadãos considerados normais.

A sociedade, ao colocar as pessoas desviantes em uma condição de inferioridade corpórea e de incapacidade produtiva, acaba por gerar uma estratificação social com limites muito claros quanto às possibilidades de realização pessoal, profissional e afetiva de seus membros.

Essa relação de dominação e imposição de valores é descrita por Freire quando reflete sobre a relação entre o que denomina de "sociedadesujeito" e "sociedade-objeto". A primeira seria aquela mandatária, definida também como sociedade matriz. A "sociedade-objeto" seria aquela dominada, periférica e não reflexiva. Diz ele o seguinte:

Nestas sociedades se instala uma elite que governa conforme as ordens da sociedade diretriz. Esta elite impõe-se às massas populares. Esta imposição faz com que ela esteja sobre o povo e não com o povo. As elites prescrevem as determinações às massas. Estas massas estão sob o processo histórico. Sua participação na história é indireta. Não deixam marcas como sujeitos, mas como objetos. (2003, p. 34)

Mas o homem tem a capacidade de ir além das fronteiras, sendo esta uma das significativas vantagens dos seres humanos, isto é, a de se terem tornado capazes de ir além de seus condicionantes.

É fundamental o homem assumir o outro como sujeito. Qualquer discriminação é imoral e lutar contra ela é um dever, por mais que se reconheça a força dos condicionamentos a enfrentar.

Saber que devo respeito à autonomia, à dignidade e à identidade [...] e, na prática, procurar a coerência com este saber, me leva inapelavelmente à criação de algumas virtudes ou qualidades sem as quais aquele saber vira inautêntico, palavreado vazio e inoperante. (FrEIRE, 1996, p. 69) 
Quanto mais se impõe ao homem a passividade, tanto mais ingenuamente, em lugar de transformar, tende a adaptar-se ao mundo, à realidade parcializada. Na medida em que essa visão anula o poder criador dos homens ou minimiza, estimula sua ingenuidade e não sua criticidade, satisfazendo aos interesses dos opressores, que, para estes, o fundamental não é o desnudamento do mundo, sua transformação, pois o seu humanitarismo, e não-humanismo, está em preservar a situação de que a generosidade a que se refere por isso mesmo é que reage, até instintivamente, contra qualquer tentativa de um pensar autêntico que não se deixa emaranhar pelas visões parciais da realidade, buscando sempre os nexos que prendem um ponto ao outro ou um problema a outro (FrEIRE, 2002).

Tal reflexão remete-nos ao conceito freireano de inconclusão. A consciência do homem de seu inacabamento é que o distingue dos demais seres vivos. É, portanto, condição sine qua non do ser humano. Nas palavras de Freire (1996, p. 64-65),

É na inconclusão do ser, que se sabe como tal, que se funda a educação como processo permanente. Mulheres e homens se tornaram educáveis na medida em que se reconheceram inacabados. Não foi a educação que fez mulheres e homens educáveis, mas a consciência de sua inconclusão é que gerou sua educabilidade. É também na inconclusão de que nos tornamos conscientes e que nos inserta no movimento permanente de procura que se alicerça a esperança. "Não sou esperançoso", disse certa vez, por pura teimosia, mas por exigência ontológica.

A inconclusão, a consciência do inacabamento, a busca de uma condição melhor é a principal característica do homem. Ele está em constante processo de transformação, de seu fazer-se homem. Em momento algum, Freire deixa de fora a condição humana de sujeito histórico.

Em relação à deficiência, a concepção freireana de inacabamento desloca o sentido da incapacidade para o de promoção do ser humano engajado como sujeito histórico, independente de sua condição física, mental ou sensorial. "Ser inacabado" não pode, à luz do pensamento de Paulo Freire, ser entendido como "ser deficiente".

Faz-se necessário reconhecer o homem como sujeito histórico, capaz de inserir-se na realidade histórica de forma crítica, atuando no 
mundo e com o mundo, de forma a criar e recriar a sua existência, baseando-se no seu cotidiano. Para Freire, o homem só se conscientiza quando está no mundo e com o mundo, quando toma como sua a responsabilidade de participar e co-participar com os outros. É nessa situação que o homem torna-se homem, que atua no cotidiano da história, que se constrói junto ao outro, de forma coletiva.

A conscientização está evidentemente ligada à utopia, implica em utopia. Quanto mais conscientizados nos tornamos, mais capacitados estamos para sermos anunciadores e denunciadores, graças ao compromisso de transformação que assumimos. (FrEIRE, 2001c, p. 28)

A conscientização é concebida como um ato de conhecimento, compreensão do mundo real que cerca o homem. Por ela, o homem adentra as causas profundas dos acontecimentos da realidade social, e, por conhecê-las, tende a comprometer-se com a realidade, sinalizando o tipo de sociedade e de mundo que se acha comprometido a construir. Assim, os oprimidos vão desvelando o mundo da opressão e vão comprometendo-se, na práxis, com a sua transformação. A realidade, ao ser transformada, passa a ser uma realidade dos homens em processo de permanente libertação, tanto dos oprimidos quanto dos opressores.

Isso acarretará uma ação profunda através da qual

se enfrentará, culturalmente, a cultura da dominação, que acontecerá num primeiro momento por meio da mudança da percepção do mundo opressor por parte dos oprimidos e num segundo momento pela expulsão dos mitos criados e desenvolvidos na estrutura opressora e que se preservam como espectros míticos, na estrutura nova que surge da transformação revolucionária. (FrEIRE, 2002, p. 41-42)

Para Freire, a relação sujeito-sujeito e sujeito-mundo são indissociáveis. Como ele afirma, "Ninguém educa ninguém, ninguém educa a si mesmo, os homens se educam entre si, mediatizados pelo mundo" (2002, p. 68).

Dessa forma, o diálogo se impõe como caminho pelo qual os homens ganham significação como homens. É uma exigência existencial, é o encontro em que se solidarizam o refletir e o agir de seus sujeitos endereçados ao mundo a ser transformado e humanizado. É mister que o pensar seja verdadeiro para que se tenha um diálogo também verdadeiro 
e crítico, objetivando superar, assim, a contradição que se instaura entre opressor-oprimido. Diz Freire (1996, p. 132):

Por isso é que, acrescento, quem tem o que dizer deve assumir o dever de motivar, de desafiar quem escuta, no sentido de que, quem escuta diga, fale, responda. É intolerável o direito que se dá a si mesmo o educador autoritário de comportar-se como proprietário da verdade de que se apossa e do tempo para discorrer sobre ela. Para ele, quem escuta sequer tem tempo próprio pois o tempo de quem escuta é o seu, o tempo de sua fala. Sua fala, por isso mesmo, se dá num espaço silenciado e não num espaço com ou em silêncio. Ao contrário, o espaço do educador democrático, que aprende a falar escutando, é cortado pelo silêncio intermitente de quem, falando, cala para escutar a quem, silencioso, não silenciado, fala.

As considerações ora tecidas sobre o pensamento de Paulo Freire autorizam-nos afirmar que o eminente educador brasileiro posicionou-se no ideário inclusivista, uma vez que todo o seu discurso reflete uma postura antidiscriminatória e a favor do reconhecimento e do respeito pela diferença.

Homens, mulheres, deficientes, não-deficientes, crianças, jovens, adultos, enfim, todos, indistintamente, precisam participar do processo de mudança.

Acreditar em uma sociedade mais justa, mais humana e mais igualitária significa estar inserido na luta pela superação da relação opressor-oprimido, luta esta que, por uma questão de princípio, ninguém pode estar de fora. Não se trata de algo impossível, mas de uma proposta prática de superação dos aspectos opressores percebidos na realidade. Essa rebeldia é, para Paulo Freire, uma atitude necessária para a ruptura com as práticas discriminatórias e segregadoras utilizadas pelos opressores na manutenção do paradigma da exclusão. Diz ele:

É preciso, porém, que tenhamos na resistência que nos preserva vivos, na compreensão do futuro como problema e na vocação para o ser mais como expressão da natureza humana em processo de estar sendo, fundamentos para a nossa rebeldia e não para a nossa resignação em face das ofensas que nos destroem o ser. Não é na resignação mas na rebeldia em face das injustiças que nos afirmamos.

Uma das questões centrais com que temos de lidar é a promoção de posturas revolucionárias que nos engajam no processo radical de 
transformação do mundo. A rebeldia é ponto de partida indispensável, é deflagração da justa ira, mas não suficiente. A rebeldia enquanto denúncia precisa se alongar até uma posição mais radical e crítica, a revolucionária, fundamentalmente anunciadora. A mudança do mundo implica a dialetização entre a denúncia da situação desumanizante e o anúncio de sua superação, no fundo, o nosso sonho. (FREIRE, 1996, p. 87-88)

Esse movimento de ruptura pode ser traduzido pelo inédito-viável, ou seja, algo inédito, ainda não claramente conhecido e vivido, mas sonhado. Conforme diz Ana Maria Freire, nas notas da obra Pedagogia da esperança, de Paulo Freire (2001b, p. 206):

Esse "inédito-viável" é, pois, em última instância, algo que o sonho utópico sabe que existe mas que só será conseguido pela práxis libertadora que pode passar pela teoria da ação dialógica de Freire ou, evidentemente, porque não necessariamente só pela dele, por outra que pretenda os mesmos fins.

Acreditar na transformação do mundo pelos caminhos freireanos, da comunhão, do diálogo, da conscientização e da libertação, é acreditar na capacidade de todos os seres humanos alimentarem juntos o ideal utópico da mudança, no qual a inclusão é, nos nossos dias, um dos maiores de todos os sonhos: uma realidade em que opressores e oprimidos se façam, de fato, livres dos elos aprisionantes do preconceito, da discriminação e da injustiça.

\section{ABSTRACT}

Many conditions are considered 'deviant' by society. Being black, elderly, a child, a woman, or disabled represent conditions of inferiority in terms of the right to fulfill one's social duties. It is in this context that social relations make themselves felt in different ways, resulting in the most diverse forms of prejudice and control. Paulo Freire always took a vehement stance against such attitudes. The categories of historicity, inconclusiveness, conscientization, communion, dialogue and freedom were used in this study. Freire's stance against discrimination and segregation places him as one of the most important theoreticians of the movement for rupture with the paradigm of exclusion, in the search for the establishment of what is nowadays known as the paradigm of social inclusion.

Key words: inclusion;exclusion; diversity; paradigm. 


\section{REFERÊNCIAS}

FREIRE, P. Algumas reflexões em torno da utopia. In: FREIRE, A. M. de A. (Org.). Pedagogia dos sonhos possíveis. São Paulo: Unesp, 2001a. p. 85-86.

Educação e mudança. 27. ed. Rio de Janeiro: Paz e Terra, 2003.

. Pedagogia da autonomia: saberes necessários à prática educativa. 5 . ed. Rio de Janeiro: Paz e Terra, 1996.

Pedagogia da esperança: um reencontro com a pedagogia do oprimido. 8. ed. Rio de Janeiro: Paz e Terra, $2001 \mathrm{~b}$.

. Pedagogia do oprimido. 32. ed. Rio de Janeiro: Paz e Terra, 2002.

. Política e educação. 5. ed. São Paulo: Cortez, 2001c.

MARQUES, L. P. Em busca da compreensão da problemática da família do excepcional. 1992. Dissertação (Mestrado em Educação) - Departamento de Educação, Pontifícia Universidade Católica do Rio de Janeiro, Rio de Janeiro.

RIBAS, J. B. C. O que são pessoas deficientes? São Paulo: Brasiliense, 1989. 